\title{
ASO Author Reflections: We No Longer Give Ketorolac During Mastectomy. Should You?
}

\author{
Patrick J. McCormick, MD, MEng ${ }^{1,2}$ (D), and Brett A. Simon, MD, $\mathbf{P h D}{ }^{2,3}$ \\ ${ }^{1}$ Department of Anesthesiology and Critical Care Medicine, Memorial Sloan Kettering Cancer Center, New York, NY; \\ ${ }^{2}$ Department of Anesthesiology, Weill Cornell Medicine, New York, NY; ${ }^{3}$ Department of Anesthesiology and Critical \\ Care Medicine and Department of Surgery, Memorial Sloan Kettering Cancer Center, New York
}

\section{PAST}

Ketorolac is a potent nonsteroidal antiinflammatory analgesic that has become an integral part of opioid-sparing enhanced recovery after surgery pathways for mastectomy. ${ }^{1}$ Ketorolac is associated with increased risk of bleeding, but metaanalysis of trials involving other kinds of surgery does not support that association. ${ }^{2}$ A recent retrospective study of lumpectomy and mastectomy patients also found no association of ketorolac with perioperative bleeding. ${ }^{3}$

\section{PRESENT}

Our surgical center was conceived around standardized surgical pathways updated based on patient outcomes. ${ }^{4} \mathrm{We}$ became concerned about anecdotal reports of perioperative bleeding requiring a return trip to the operating room. We found that ketorolac administration was associated with more than double the odds of reoperation for bleeding after mastectomy (odds ratio $2.43 ; 95 \%$ confidence interval 1.60 , 3.70; $P<0.0001) .{ }^{5} \mathrm{We}$ also found that use of ketorolac led to only a small reduction in the need for opioid analgesics. The magnitude of the result led us to remove ketorolac from our mastectomy pathway.

(C) Society of Surgical Oncology 2021

First Received: 15 February 2021 Accepted: 16 February 2021; Published Online: 5 March 2021

P. J. McCormick, MD, MEng

e-mail: mccormp1@mskcc.org

\section{FUTURE}

Despite the single-center and retrospective nature of our study, our large sample and effect size provide persuasive evidence that holding ketorolac will improve patient outcome. Other mastectomy centers should evaluate these data and strongly consider discontinuing intraoperative ketorolac. Reoperation for bleeding is an outcome that other mastectomy ERAS programs should track, as it is less subjective than postoperative hematoma and associated with defined costs.

DISCLOSURES Dr. McCormick's spouse holds stock in Johnson \& Johnson.

\section{REFERENCES}

1. Jogerst K, Thomas O, Kosiorek HE, et al. Same-day discharge after mastectomy: breast cancer surgery in the era of ERAS. Ann Surg Oncol. Sep ;27(9):3436-45.

2. Gobble RM, Hoang HL, Kachniarz B, Orgill DP. Ketorolac does not increase perioperative bleeding: a meta-analysis of randomized controlled trials. Plast Reconstr Surg. Mar ;133(3):741-55.

3. Rojas KE, Fortes TA, Flom P, Manasseh DM, Andaz C, Borgen P. Intraoperative ketorolac use does not increase the risk of bleeding in breast surgery. Ann Surg Oncol. Oct ;26(10):3368-73.

4. Tokita H, Twersky R, Laudone V, et al. Complex cancer surgery in the outpatient setting: the Josie Robertson surgery center. Anesth Analg. Sep;131(3):699-707.

5. McCormick PJ, Assel MJ, Van Zee KJ, et al. Intraoperative ketorolac is associated with risk of reoperation after mastectomy: a single-center examination. Ann Surg Oncol. 2021. https://doi.org/ 10.1245/s10434-021-09722-4.

Publisher's Note Springer Nature remains neutral with regard to jurisdictional claims in published maps and institutional affiliations. 